\title{
Effects of Pyrolysis on Biogas Production during Anaerobic Co- digestion of Corn Stover
}

\author{
Risu NA ${ }^{1}$, Keisuke KushimA ${ }^{1}$, and Naoto SHIMIZU ${ }^{2 *}$ \\ ${ }^{1}$ Graduate School of Agriculture, Hokkaido University, 9-9 Kita, Kita-ku, Sapporo, Hokkaido 060-8589, Japan \\ ${ }^{2}$ Research Faculty of Agriculture, Hokkaido University, 9-9 Kita, Kita-ku, Sapporo, Hokkaido 060-8589, Japan
}

\begin{abstract}
The effects of pyrolysis pretreatment on biogas production during anaerobic co-digestion of corn stover were studied. The corn stover characteristics were investigated by performing thermogravimetric analysis using a heating rate of $10.0^{\circ} \mathrm{C} / \mathrm{min}$ and an air atmosphere at atmospheric pressure. Corn stover aliquots pretreated in an electric furnace at $100^{\circ} \mathrm{C}$ for $360 \mathrm{~min}$, $200^{\circ} \mathrm{C}$ for $15 \mathrm{~min}$, and $300^{\circ} \mathrm{C}$ for $5 \mathrm{~min}$ were used. Untreated and pretreated corn stover samples were analyzed by scanning electron microscopy and other methods, and the bulk densities and component ratios were compared to identify changes caused by the pretreatments. The amounts of total solids, volatile solids, volatile fatty acids, and total ammonia nitrogen produced when the stover samples were anaerobically digested were measured. The biogas production rate and the methane concentration in the biogas were determined. The substrate-specific methane yields were determined, and the relationships between the yields and pretreatment conditions were assessed. The sample pretreated at $300^{\circ} \mathrm{C}$ for 5 min produced the most biogas. The corn stover total solid bulk density was directly related to the substrate-specific methane yield, the substratespecific methane yield decreasing as the total solid bulk density increased.
\end{abstract}

\section{Introduction}

People are becoming increasingly concerned about global warming and environmental conservation. Anaerobic codigestion using biomass as a raw material decreases the environmental burden of waste and allows energy to be recovered from waste, helping to decrease the amounts of greenhouse gases emitted.

Inedible parts of crops and forestry residues are forms of biomass that can be effectively anaerobically digested. Lignocellulosic biomass in non-edible parts of crops is complex and includes carbohydrates (e.g., lignin, cellulose, and hemicellulose), pectin, proteins, salts, and minerals. There is currently much interest from both economic and environmental points of view in using lignocellulosic biomass to produce renewable energy. China, the largest developing country, has very serious energy supply and environmental problems. In 2015, $1.04 \times 10^{9} \mathrm{t}$ of main crop straw were produced in China, but only $90 \times 10^{6} \mathrm{t}$ were collected (National Development and Reform Commission, People's Republic of China, 2015). China produces large amounts of maize (corn). A total of $38 \times 10^{6}$ ha $(33.9 \%$ of the total area used to grow grain) was used to grow corn in 2015 (National Bureau of Statistics of China, 2017). It would therefore be advantageous to use corn stover in some way. More than
$50 \%$ of corn stover is hardly decomposable organic matter (lignin and hemicellulose), so corn stover needs to be pretreated to allow it to be effectively anaerobically digested (Wang et al., 2015).

Biomass can be pretreated using various methods (singly or in combination) such as physical grinding, thermal decomposition, and acid, alkali, and bacterial treatments. Conventional pretreatments generally involve using acids, alkalis, organic solvents, and oxidizing agents. These methods can cause environmental pollution and are expensive and technically difficult. A sustainable, environmentally benign, and cheap method for pretreating lignocellulosic biomass before anaerobic digestion is performed is therefore required (Zheng et al., 2014).

Improving anaerobic digestion efficiency and increasing the amount of biogas produced are the main objectives of thermal pretreatments, but thermal pretreatment also offers the advantages that no chemicals are required and the methods are relatively environmentally benign. It has previously been found that cellulose, hemicellulose, and lignin in corn stover can be thermally decomposed under appropriate conditions. However, most previous studies have been focused on assessing pyrolysis pretreatments by measuring the removal rates of various components (Wang et al., 2016; Brown et al., 2012). The objective of this study was to

\footnotetext{
${ }^{*}$ Corresponding author: shimizu@bpe.agr.hokudai.ac.jp
} 
assess the effects of pyrolysis pretreatment of corn stover on biogas production during anaerobic co-digestion from the perspective of changes in the corn stover physical properties (bulk density and surface morphology) caused by pyrolysis.

\section{Materials and Methods}

\subsection{Raw materials and digestate}

The characteristics of the raw materials used in the study are shown in Table 1. Corn stover (variety New Dent, grown for 105 d) harvested in 2017 and 2018 from a farm owned by Hokkaido University was pulverized to give pieces with diameters $\sim 10 \mathrm{~mm}$. Food waste collected from the Hokkaido University central restaurant was ground using a food processor. Digestate was obtained from a biogas plant operated by the Hokkaido University farm.

Table 1. Characteristics of the materials used in the study (TS $=$ total solid content, $\mathrm{VS}=$ volatile solid content, $\mathrm{VFA}=$ volatile fatty acid content, $\mathrm{TAN}=$ total ammonia nitrogen content, $\mathrm{C}=$ carbon content, $\mathrm{N}=$ nitrogen content)

\begin{tabular}{|c|c|c|c|c|c|c|c|}
\hline & $\mathrm{pH}$ & $\begin{array}{c}\text { TS } \\
{[\% \text { w.b. }]}\end{array}$ & $\begin{array}{c}\text { VS } \\
{[\% \text { w.b. }]}\end{array}$ & $\begin{array}{c}\text { VFA } \\
{[\mathrm{mg} / \mathrm{L}]}\end{array}$ & $\begin{array}{c}\text { TAN } \\
{[\mathrm{mg} / \mathrm{L}]}\end{array}$ & $\begin{array}{c}\mathrm{C} \\
{[\% \text { \%.b. }]}\end{array}$ & $\begin{array}{c}\mathrm{N} \\
{[\% \text { \%.b. }]}\end{array}$ \\
\hline Digestate & 7.93 & 6.04 & 4.55 & $0.73 \times 10^{3}$ & $2.13 \times 10^{3}$ & - & - \\
\hline Corn stover(2017) & - & 11.4 & 9.71 & - & - & 35.2 & 0.60 \\
\hline Corn stover(2018) & - & 22.1 & 20.0 & - & - & 35.2 & 0.60 \\
\hline Food waste & - & 19.7 & 17.5 & - & - & 30.0 & 3.00 \\
\hline
\end{tabular}

\subsection{Experimental conditions}

The corn stover was thermogravimetrically analyzed using a Thermo plus EVO II TG 8120 instrument (Rigaku, Tokyo, Japan). The results, presented in Figure 1, indicated that the pretreatment process had three stages. The first stage was dehydration in the temperature range $23-60{ }^{\circ} \mathrm{C}$, in which $77.5 \%$ of the raw corn stover weight was lost as moisture. The second stage was active pyrolysis in the temperature range $160-377^{\circ} \mathrm{C}$, in which $12.4 \%$ of the fresh corn stover weight was lost, mainly through the loss of volatile matter and tar. The third stage was passive pyrolysis in the temperature range 377$607{ }^{\circ} \mathrm{C}$, in which $5.8 \%$ of the fresh corn stover weight was lost, mainly through the loss of fixed carbon (Jutakridsada et al., 2016).

The thermogravimetric analysis results led us to use three pretreatment temperatures, $100{ }^{\circ} \mathrm{C}$ (in stage 1) $200{ }^{\circ} \mathrm{C}$ (in stage 2 ), and $300{ }^{\circ} \mathrm{C}$ (also in stage 2 ). The stage 1 temperature was used to treat the corn stover harvested in 2017 in the first week of anaerobic digestion tests. The stage 2 temperatures were used to treat the corn stover harvested in 2018 in the second and third weeks of the anaerobic tests. The first weight loss stage was dehydration, so every sample was pretreated at $100{ }^{\circ} \mathrm{C}$ for 360 min to give a low moisture content.

The most important anaerobic digestion operating factors are the organic load and $\mathrm{C} / \mathrm{N}$ ratio. The organic loading rate was 1.5 (g volatile solids (VS))/(L d) (Zhou et al., 2017). The $\mathrm{C} / \mathrm{N}$ ratio was 40 (to minimize ammonia production) (Nakajima et al., 2016; Banks and Heaven, 2013). The amount of raw material added was calculated using equations (1) and (2). Raw material and digestate were added to a $235 \mathrm{~L}$ reactor four times each week (on Monday, Tuesday, Thursday, and Friday). Anaerobic conditions were maintained by supplying nitrogen to the vessel after adding material, then the vessel was heated to $\sim 53{ }^{\circ} \mathrm{C}$. The pretreatment conditions used for the FO300 electric furnace (Yamato, Japan) and a flow chart illustrating the anaerobic digestion process are shown in Figure 2.

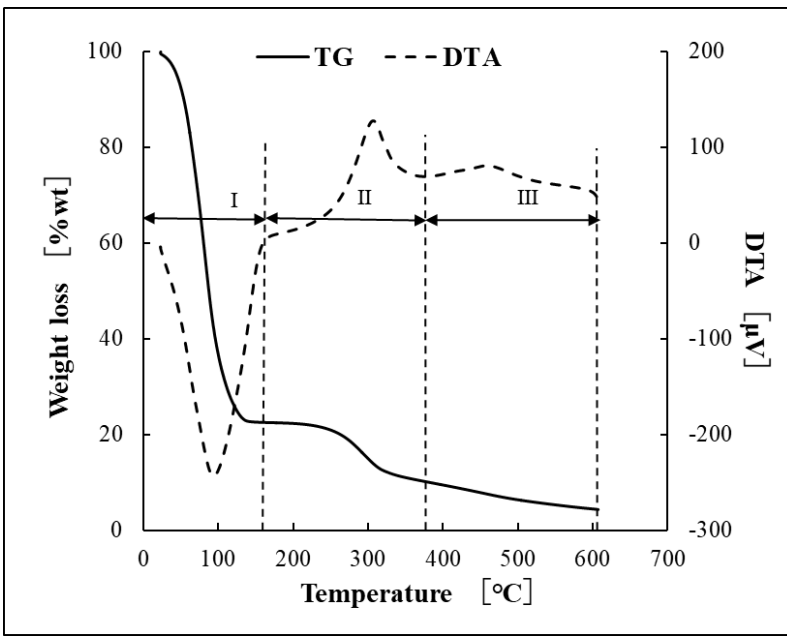

Figure 1. Thermogravimetric analysis results for the corn stover

$O L R=\frac{\text { Volatile solids in feedstock }[\mathrm{g}]}{\text { Volume }[\text { L digestate }] \times \text { Residence time }[\mathrm{d}]}$

$C / N=\frac{\text { Carbon content of feedstock }}{\text { Nitrogen content of feedstock }}$

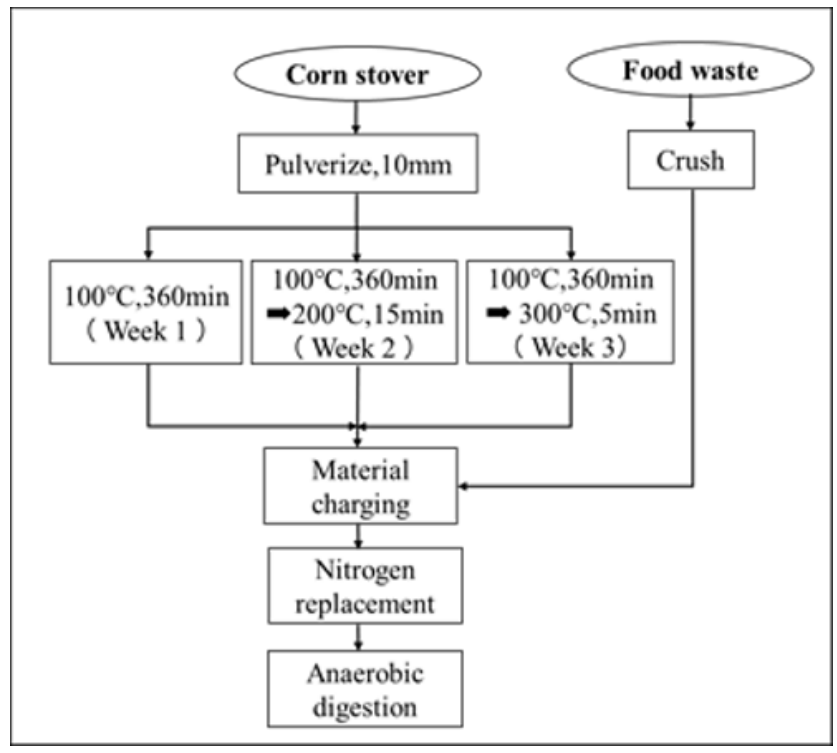

Figure 2. Anaerobic digestion process flow chart

\subsection{Bulk density measurement}

The bulk density of the corn stover was measured using the water displacement method, using a $25 \mathrm{~mL}$ graduated 
cylinder and equation (3), in which $\mathrm{W}_{1}$ is the sample dry weight, $\mathrm{W}_{2}$ is the weight of the sample in water, and $\mathrm{W}_{3}$ is the weight of the sample and the added water. Each measurement was made in triplicate, and the mean result was calculated.

$$
\text { Bulk density }=\frac{W_{1}}{W_{3}-W_{2}} \times \rho_{\mathrm{w}}
$$

\subsection{Biogas production rate, methane concentration, and substrate-specific methane yield measurements}

The biogas production rate was determined using a wet gas meter (Shinagawa Corporation, Tokyo, Japan) and recorded using a HIOKI LR5000 data logger (Hioki E.E. Corporation, Nagano, Japan). The biogas composition was determined using a Geotech BIOGAS 5000 gas monitor (QED Environmental Systems, Dexter, MI, USA), focusing on the methane and carbon dioxide concentrations. The amount of biogas generated was determined every $12 \mathrm{~h}$, and the methane ratio in the biogas was determined twice each day to allow the amount of methane generated to be calculated. The substratespecific methane yield indicated the amount of methane generated per unit of volatile solids added, and was used to allow the effectiveness of the pretreatment to be assessed.

\section{Results and Discussion}

\subsection{Corn stover component ratios}

The corn stover component ratios are shown in Figure 3. The pretreatment generally changed the corn stover composition ratios by decreasing the moisture content and volatile solid content. However, the volatile solid contents of the raw sample and the week 2 sample were not significantly different.

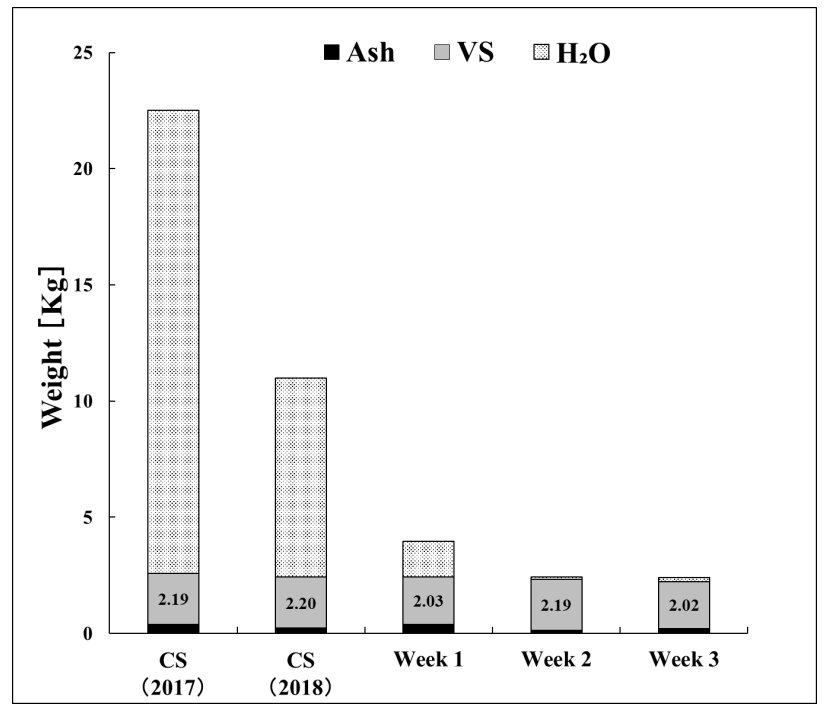

Figure 3. Component ratios for the pretreated corn stover samples

\subsection{Scanning electron microscopy}

Structural changes caused by pretreatment were assessed by subjecting the samples to scanning electron microscopy analysis using a JSM-6301F system (JEOL, Tokyo, Japan). The raw material contained leaves and stalks, and these were analyzed separately. Scanning electron microscopy images of the samples are shown in Figure 4. It can be seen that cracks on the straw surfaces became more severe as the pretreatment temperature increased but that the leaf surfaces changed little.
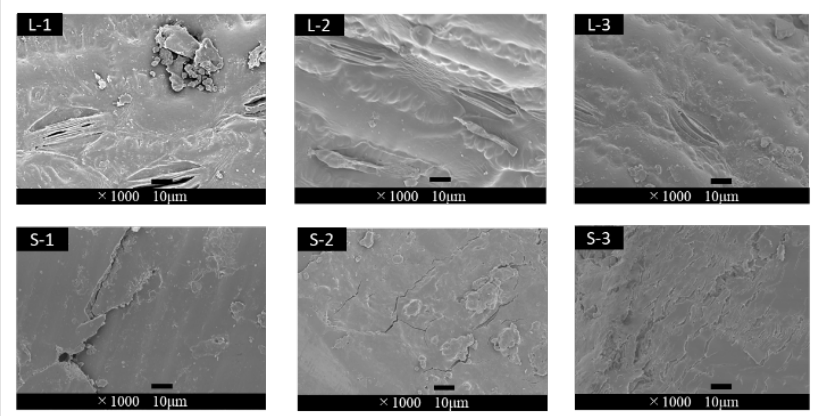

Figure 4. Scanning electron microscopy images of corn stover samples ( $\mathrm{L}$ and $\mathrm{S}$ indicate leaf and stalk, respectively, and each number following L- or Sindicates the number of weeks)

\subsection{Corn stover bulk density and total solid content}

The corn stover bulk density decreased as the pretreatment temperature increased. Biomass consists of total solids and moisture, so the total solid bulk density was calculated using the mass of a sample with the moisture content subtracted. The results are shown in Figure 5.

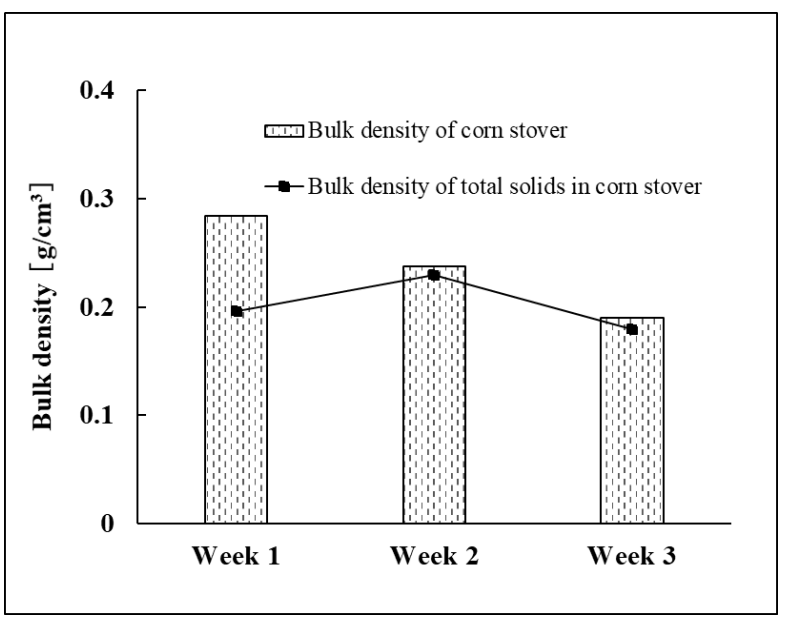

Figure 5. Bulk densities of the corn stover and of the corn stover total solids

\subsection{Anaerobic digestion}

3.4.1 Anaerobic digestion of the liquid fraction 
The whole digestion process was assessed by measuring the digestate components twice (on Monday and Thursday) each week, focusing on the total solid, volatile solid, volatile fatty acid, and total ammonia nitrogen contents. The results are shown in Figure 6. The results indicated that the total solid and ash contents increased slightly over time. The volatile solid content was relatively stable throughout the process. The amounts of volatile fatty acids and total ammonia nitrogen produced during digestion are shown in Figure 7. The amount of volatile fatty acids produced increased over time, particularly in the third week. Volatile fatty acids are intermediate products of methane production during anaerobic digestion, and will be assessed along with the biogas production rate and methane concentration below. The total ammonia nitrogen concentration did not change markedly over time. The total ammonia nitrogen concentration remained below the safe concentration of $2500 \mathrm{~mL} / \mathrm{L}$ throughout the process.

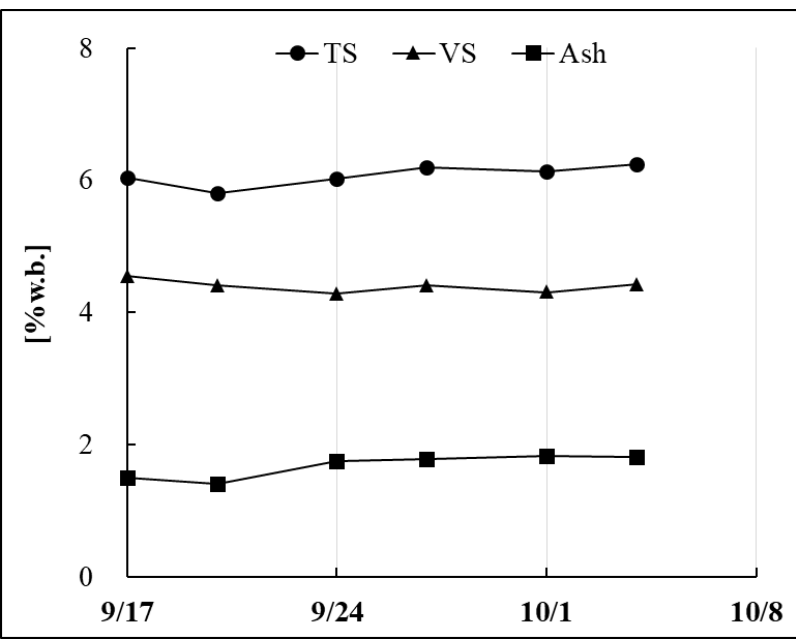

Figure 6. Total solid (TS), volatile solid (VS), and ash contents of the digestate during the anaerobic digestion process

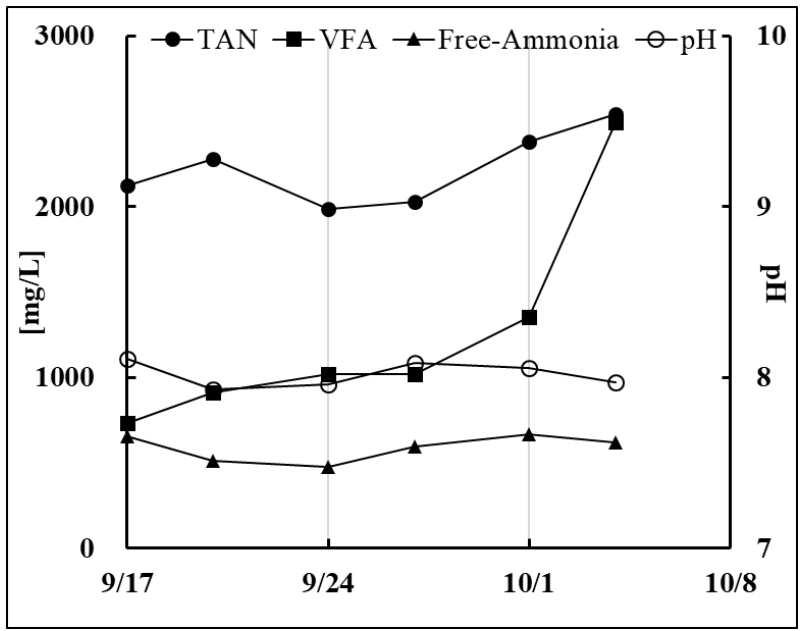

Figure 7. Total ammonia nitrogen (TAN),

volatile fatty acid (VFA), and free ammonia contents and $\mathrm{pH}$ values of the digestate during the anaerobic digestion process

\subsubsection{Biogas production rate and methane concentration}

The biogas production rates and methane concentrations are shown in Figures 8 and 9, respectively. The biogas production rate increased throughout the study, and combining these results with the corn stover bulk density results we concluded that the corn stover bulk density was related to the biogas production rate. The biogas production rate increased as the bulk density decreased. but the lowest methane concentration was found on the 27 th of September because the mixer had stopped. The percentage total solids in the raw material was determined, and the values for weeks 1,2 , and 3 were $49 \%, 66 \%$, and $65 \%$, respectively. We concluded that a high percentage of total solids in the raw materials could cause the equipment to fail. The digestion process remained successful in week 3 because the surface area available to microorganisms was high.

The methane concentration and production rate continued to increase in week 3 . Combined with the volatile fatty acid response, we concluded that larger amounts of volatile fatty acids were produced in the initial hydrolysis phase during anaerobic digestion when the substrate had been pretreated than when the substrate had not been pretreated. This was shown by a strong increase in the volatile fatty acid concentration in week 3 , which caused an imbalance in the process. Similar conclusions were drawn in previous studies (Lee et al., 2015; FrankWhittle et al., 2014).

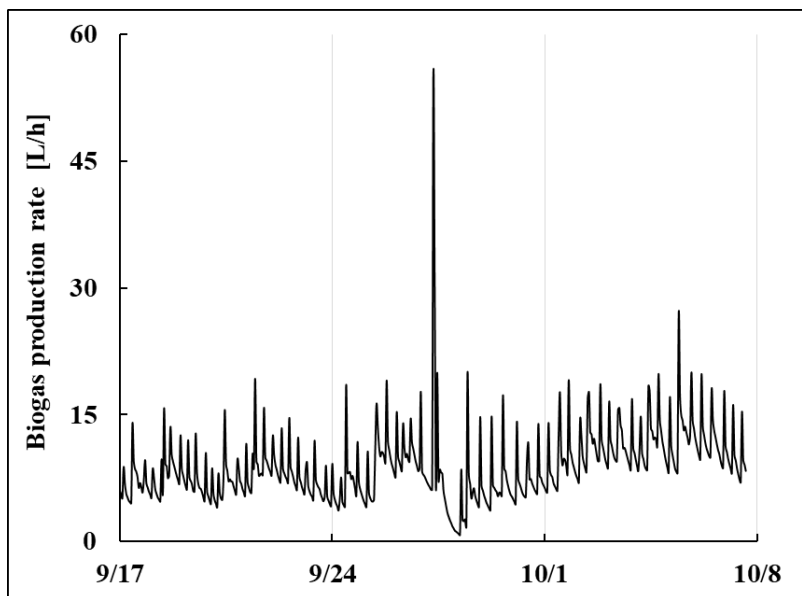

Figure 8. Biogas production rate over time

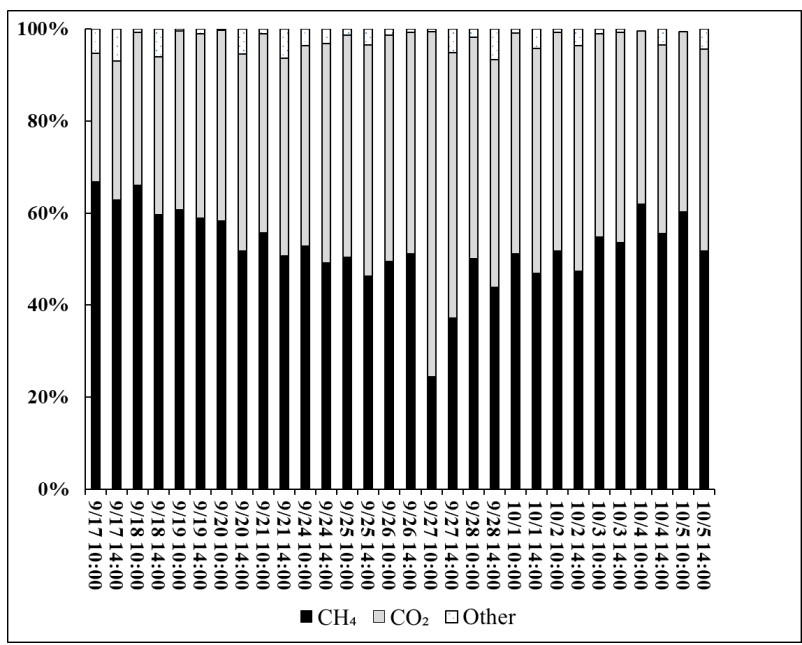

Figure 9. Methane concentration over time 


\subsubsection{Substrate-specific methane yield}

The substrate-specific methane yields are shown in Figure 10. Volatile solids were lost during pretreatment, so the substrate-specific methane yield was calculated by subtracting the volatile solids lost during pretreatment from the total volatile solid content. The highest substratespecific methane yield was found in week 3 , and the substrate-specific methane yield decreased as the total solid bulk density increased. A straight line fitted a plot of the total solid bulk densities and substrate-specific methane yields well $\left(\mathrm{R}^{2} 0.94\right)$.

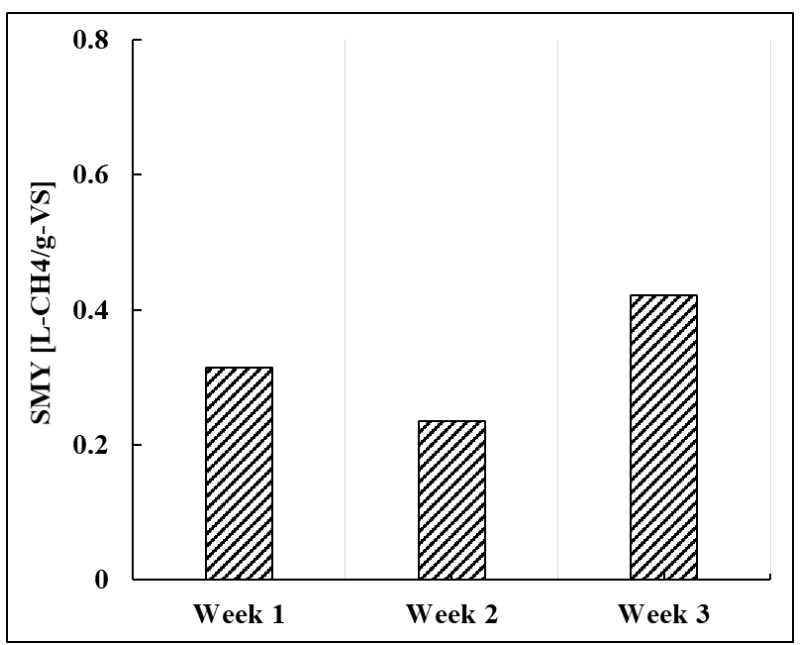

Figure 10. Substrate-specific methane yields for the different pretreatments

\subsection{Discussion}

The effects of pyrolysis on biogas production during the anaerobic co-digestion of corn stover under different conditions were assessed by determining the substratespecific methane yields. The highest yield $\left(0.45 \mathrm{~L}\right.$ of $\mathrm{CH}_{4}$ per gram of volatile solids) was found in week 3 when corn stover pretreated at $300{ }^{\circ} \mathrm{C}$ for 5 min was used. Pretreating corn stover at $300{ }^{\circ} \mathrm{C}$ for $5 \mathrm{~min}$ is easily and quickly achieved, and will improve the digestion efficiency and the amount of biogas produced.

\section{Conclusions}

The pretreatments decreased the bulk density, increased the specific surface area, and increased the porosity of the corn stover. Contact between the raw material and microorganisms therefore increased, and this increased the processing efficiency. The total solid bulk density directly affected the methane production rate.

\section{Acknowledgements}

We thank Gareth Thomas, $\mathrm{PhD}$, from Edanz Group for editing a draft of this manuscript.

\section{References}

Banks, C. J. and S. Heaven; "Optimisation of Biogas Yields from Anaerobic Digestion by Feedstock Type" The Biomass Handbook, pp. 131-161, Elsevier, Amsterdam, the Netherland (2013)

Brown, D., J. Shi, and Y B. Li, "Comparison of Solidstate to liquid Anaerobic Digestion of Lignocellulosic Feedstocks for Biogas Production," Bioresource and Technology. 384, 379-386 (2012)

Frank-Whittle, I. H., A. Walter, C. Ebner, and H. Insam; "Investigation into the Effect of High Concentrations of Volatile Fatty Acids in Anaerobic Digestion on Methanogenic Communities," Waste Management, 34, 2080-2089 (2014)

Jutakridsada, P., R. Sriprasoed, N. Patikarnmonthon, and K. Kamwilaisak; "Comparison Study of Sugarcane Leaves and Corn Stover as a Potential Energy Source in Thermal pretreatment,"Energy Procedia, 100, 26-29 (2016)

Lee, D.-J., S.-Y. Lee, J.-S. Bae, J.-G. Kang, K.-H. Kim, S.-S. Rhee, J.-H. Park, J-S. Cho, J. Chung, and D-C. Seo; "Effect of Volatile Fatty Acid Concentration on Anaerobic Degradation Rate from Field Anaerobic Digestion Facilities Treating Food Waste Leachate in South Korea" Journal of Chemistry, 2015, 640717 (2015)

Nakajima, S., N. Shimizu, H. Ishiwata, and T. Ito,; "The Start-up of Thermophilic Anaerobic Digestion of Municipal Solid Waste," Journal of the Japan Institute of Energy, 95, 645-647 (2016)

National Development and Reform Commission, People's Republic of China; Comprehensive utilization rate of straw in China was over $80 \%$ in 2015 , National Development and Reform Commission, People's Republic of China, Beijin, China (2015)

National Bureau of Statistics of China; Announcement of the National Bureau of Statistics on Grain Production in 2015, National Bureau of Statistics of China (2015)

Wang, F., W. S. Niu, A. D. Zhang, and W. M. Yi; "Enhanced Anaerobic Digestion of Corn Stover by Thermo-chemical Pretreatment," International Journal of Agricultural and Biological Engineering, 8, 84-90 (2015)

Wang, F., D. L. Zhang, H. K. Wu, W. M. Yi, P. Fu, Y G. $\mathrm{Li}$, and Z. H. Li ; "Enhancing Biogas Production of Corn Stover by Fast Pyrolysis Pretreatment," Bioresource and Technology, 218, 731-736 (2016)

Zheng, Y., J. Zhao, F Q. Xu, and Y. B. Li; "Pretreatment of Lignocellulosic Biomass for Enhanced Biogas Production," Progress in Energy and Combustion Science, 42, 35-53 (2014)

Zhou, J., J. Yang, Q. Yu, X. Y. Yang, X. X. Xie, L J. Zhang, P. W. Wei, and H. H. Jia ; "Different Organic Loading Rates on the Biogas Production during the Anaerobic Digestion of Rice Straw: A Pilot Study," Bioresource and Technology, 244, 865-871 (2017) 